\title{
Unicondylar knee arthroplasty in the inpatient vs. outpatient setting: Impact on process time
}

Ibrahim Mamdouh Zeini*1, Meghan Hufstader Gabriel ${ }^{2}$, Xinliang Liu ${ }^{2}$, Alice Noblin² ${ }^{2}$ Bernardo Ramirez ${ }^{2}$, J. Mandume Kerina $^{3}$

${ }^{1}$ Orlando Health Orthopedic Institute, Sports Medicine Division, United States

${ }^{2}$ Department of Health Management and Informatics, University of Central Florida, United States

${ }^{3}$ Surgical Practice Resource Group of Florida, United States

Received: January 18, 2018

Accepted: April 3, 2018

Online Published: April 13, 2018

DOI: $10.5430 /$ jha.v7n3p17

URL: https://doi.org/10.5430/jha.v7n3p17

\begin{abstract}
Objective: There is a lack of research on the impact of transitioning inpatient procedures to the outpatient setting, specifically on process time. Unicondylar knee arthroplasty (UKA) presents an opportunity for further investigation as it is already in the early stages of transitioning to the outpatient setting.

Methods: This study analyzed the medical records of 1,075 patients who received UKA from a single surgeon (400 in the outpatient setting and 675 in the inpatient setting). Time in Pre-Op, surgery time, and time in post-anesthesia care unit (PACU) were recorded and compared between inpatient and outpatient settings using Ordinary Least Squares Regression models.

Results: Outpatient UKAs outperformed inpatient UKAs across two out of three process time variables even after controlling for comorbidities, social history, demographics, and surgery related characteristics. Actual surgery time was no different between the two settings.

Conclusions: This study demonstrated that UKA performed in the outpatient setting is associated substantial time savings preoperatively and postoperatively compared with cases performed in the inpatient setting. More research is needed to compare other outcome measures such as patient outcomes of UKA between the two settings. Implications beyond time savings should consider supply and human resources costs.
\end{abstract}

Key Words: Outpatient vs. inpatient, Transitioning to outpatient-centered care, Knee

\section{INTRODUCTION}

With the advancement of medical technology, surgical procedures have been shifting from the inpatient setting to the outpatient setting. This presents an opportunity to lower health care costs while maintaining the quality of care. Yet, few studies have examined the implications of transitioning surgical procedures from the inpatient to outpatient setting on process time. ${ }^{[1]}$
One procedure that is in the early stages of being performed in the outpatient setting is unicondylar knee arthroplasty (UKA). Performing UKAs in the outpatient setting presents many potential benefits. One of the most appealing factors that patients experience from outpatient UKAs is that they are discharged home the same day as the surgery, thus eliminating hospital stay. ${ }^{[2]}$ There is less risk of exposure to facility-borne infections as patients spend less time in the

*Correspondence: Ibrahim Mamdouh Zeini; Email: Ibrahim.Zeini@orlandohealth.com; Address: Orlando Health Orthopedic Institute, Sports Medicine Division, 1222 S. Orange Ave., 5th Floor, Mailpoint 854, Orlando, FL 32806, United States. 
facility. Significant factors in the inpatient setting may include overhead of the entire hospital, staffing, equipment, and infrastructure costs. ${ }^{[3]}$ The costs in the outpatient setting are reduced because there is less overhead associated with performing the surgeries, which in turn leads to less cost shifting. ${ }^{[4]}$

The process time of surgeries has not been widely compared between the outpatient and inpatient setting. ${ }^{[4]}$ Process time can be measured by total throughput time, which is the calculated time from entry into the pre-surgical unit until discharge from the post-anesthesia recovery ward. The process time of a surgical procedure has an impact on the costs incurred by the facility because of shortened overall time in the pre-surgical ward, operating room, and the post-anesthesia recovery ward. ${ }^{[5]}$

Significant gaps exist in the research when it comes to assessing the performance of UKAs in the outpatient as compared to the inpatient setting. In fact, researching all variations of knee procedure types (unicondylar, unicompartmental or partial) and knee procedures (arthroplasty or replacement) with respect to the transition from inpatient to outpatient surgery has not yielded a large number of peer-reviewed literature sources. ${ }^{[2,4,6]}$ This study aimed to compare the process time of UKA performed in the inpatient and outpatient settings, including time in the ambulatory surgical unit (ASU) and Pre-Op, time in surgery, and time in post-anesthesia care (PACU) and identify patient, setting, and procedure-related factors that may be associated with process time. We hypothesized that the overall process time and all three individual components would be shorter for outpatient UKA than for inpatient UKA patients.

\section{DATA AND METHODS}

\subsection{Data source}

The outpatient and inpatient data are at the provider level, from one orthopedic surgery office in Orlando, FL. The outpatient and inpatient data were captured from the patients' electronic medical records (EMR), paper records using manual data extraction, physician notes, and from Microsoft Excel reports provided by a Central Florida multi-specialty free standing ambulatory surgery center and a Central Florida regional nonprofit community hospital.

A confidentiality agreement was signed in order to access the EMR systems. The facility provided a signed letter authorizing full use and analysis of the data. In addition, approval from the University Institutional Review Board (IRB) approval was attained.

\subsection{Population studied}

This study is a retrospective analysis of UKAs with dates of service between January 1, 2009 and December 31, 2014. The data consist of 400 patients having knee surgeries in the outpatient setting and 675 patients having knee surgeries in the inpatient setting. The sample size of 1,075 individuals that will be analyzed is the total population of UKA patients seen by the practice during this timeframe.

\subsection{Measures}

The independent variable of interest is the setting in which the UKA was performed. This variable denotes whether the UKA was performed in the outpatient setting or the inpatient setting. Other variables controlled for include: patient demographics (age, gender, race, marital status); social history (employment status, alcohol consumption, tobacco use, physical activity); year of surgery (2009-2014); knee replacement type (right, left, or both); and implant type (Biomet Oxford or Zimmer Zuk). The dependent variable, process time, includes time in ASU/Pre-Op, surgery time, and time in post-anesthesia care unit (PACU). Time in ASU/Pre-Op is measured as the difference between time of entry and time of exit from the ASU/Pre-Op area. Surgery time represents the time from surgeon incision to time of closure of the surgery site. The time in PACU is measured by calculating the difference of the time of entry into the PACU from the time of exit from the PACU.

\subsection{Analysis}

Chi-square tests for association were utilized for categorical variables to determine if there are differences in variables between outpatient and inpatient UKAs. Time in the ASU/PreOp was measured by calculating the difference from time of entry into ASU/Pre-Op to time of exit from ASU/Pre-Op. Time in surgery was calculated by subtracting the surgery start time from the surgery end time. Total is the time from patient entry into the ASU/Pre-Op until discharge from the PACU - to the floor for inpatients and back home for outpatients. Ordinary Least Squares (OLS) regression models were utilized to identify the relationship between continuous dependent variables (process time) and independent variables (control variables). ${ }^{[7,8]}$

\section{RESULTS}

\subsection{Descriptive statistics}

Overall, the population was equally divided in terms of right/left knee replacement (see Table 1). Only 3 patients had both knees replaced. The most common type of implant was the Zimmer Zuk, with over $88 \%$ of patients opting for that implant. The majority of the patients were older than $65(83 \%)$ white $(93 \%)$ and married $(80 \%)$, and were nearly 
equally divided by gender ( $49 \%$ male). The majority of the population was not employed ( $85 \%)$, and were non-drinkers (62\%) and non-smokers or former smokers (94\%). There was a statistically significant difference in service setting for year of service, implant type, age, marital Status, alcohol consumption, tobacco use, and physical activity. There was not a statistically significant association between service set- ting and the following variables: knee being replaced, gender, race, and employment status.

The mean time in ASU/Pre-Op was 93.3 minutes for outpatient UKAs and 150.3 minutes for inpatient UKAs (see Figure 1). The mean time in ASU/Pre-Op for outpatient UKAs was nearly one hour less (57.1 minutes less) than the mean time in ASU/Pre-Op for inpatient UKAs.

Table 1. Demographics of sample

\begin{tabular}{|c|c|c|c|c|c|c|c|}
\hline \multirow{2}{*}{ Variable } & \multicolumn{2}{|c|}{ Total Sample } & \multicolumn{2}{|c|}{ Outpatient } & \multicolumn{2}{|c|}{ Inpatient } & \multirow{2}{*}{$p$-value } \\
\hline & $N=1,075$ & \%/Mean & $n=400$ & \%/Mean & $n=675$ & \%/Mean & \\
\hline \multicolumn{8}{|l|}{ Year of Service } \\
\hline - 2009 & 83 & $7.70 \%$ & 54 & $13.50 \%$ & 29 & $4.30 \%$ & $* * *$ \\
\hline - 2010 & 80 & $7.40 \%$ & 61 & $15.30 \%$ & 19 & $2.80 \%$ & \\
\hline - 2011 & 124 & $11.50 \%$ & 70 & $17.50 \%$ & 54 & $8.00 \%$ & \\
\hline - 2012 & 177 & $16.50 \%$ & 40 & $10.00 \%$ & 137 & $20.30 \%$ & \\
\hline - 2013 & 281 & $26.10 \%$ & 87 & $21.80 \%$ & 194 & $28.70 \%$ & \\
\hline - 2014 & 330 & $30.70 \%$ & 88 & $22.00 \%$ & 242 & $35.90 \%$ & \\
\hline \multicolumn{8}{|l|}{ Knee } \\
\hline - Left & 538 & $50.00 \%$ & 212 & $53.00 \%$ & 326 & $48.30 \%$ & \\
\hline - Right & 534 & $49.70 \%$ & 188 & $47.00 \%$ & 346 & $51.30 \%$ & \\
\hline - Both & 3 & $0.03 \%$ & 0 & $0.00 \%$ & 3 & $4.00 \%$ & \\
\hline \multicolumn{8}{|l|}{ Implant } \\
\hline - Biomet Oxford & 124 & $11.50 \%$ & 83 & $20.80 \%$ & 41 & $6.10 \%$ & *** \\
\hline - Zimmer Zuk & 951 & $88.50 \%$ & 317 & $79.30 \%$ & 634 & $93.90 \%$ & \\
\hline \multicolumn{8}{|l|}{ Age } \\
\hline - Mean & 1,075 & 72 & 400 & 69.3 & 675 & 73.06 & *** \\
\hline \multicolumn{8}{|l|}{ Gender } \\
\hline - Male & 506 & $48.80 \%$ & 195 & $48.80 \%$ & 311 & $46.10 \%$ & \\
\hline - Female & 569 & $51.20 \%$ & 205 & $51.20 \%$ & 364 & $53.90 \%$ & \\
\hline \multicolumn{8}{|l|}{ Race } \\
\hline - Not Specified & 50 & $4.70 \%$ & 21 & $5.30 \%$ & 29 & $4.30 \%$ & \\
\hline - White & 1,001 & $93.10 \%$ & 372 & $93.00 \%$ & 629 & $93.20 \%$ & \\
\hline - Black & 24 & $22.00 \%$ & 7 & $1.80 \%$ & 17 & $2.50 \%$ & \\
\hline \multicolumn{8}{|l|}{ Marital Status } \\
\hline - Not Specified & 5 & $5.00 \%$ & 4 & $1.00 \%$ & 1 & $0.10 \%$ & *** \\
\hline - Married & 862 & $80.20 \%$ & 336 & $84.00 \%$ & 526 & $77.90 \%$ & \\
\hline - Widowed & 120 & $11.20 \%$ & 23 & $5.80 \%$ & 97 & $14.40 \%$ & \\
\hline - Divorced & 33 & $3.10 \%$ & 12 & $3.00 \%$ & 21 & $3.10 \%$ & \\
\hline - Single & 51 & $4.70 \%$ & 23 & $5.80 \%$ & 28 & $4.10 \%$ & \\
\hline - Separated & 4 & $0.40 \%$ & 2 & $5.00 \%$ & 2 & $0.30 \%$ & \\
\hline \multicolumn{8}{|l|}{ Employment Status } \\
\hline - Not Employed & 916 & $85.20 \%$ & 344 & $86.00 \%$ & 572 & $84.70 \%$ & \\
\hline - Full Time & 81 & $7.50 \%$ & 28 & $7.00 \%$ & 53 & $7.90 \%$ & \\
\hline - Part Time & 78 & $7.30 \%$ & 28 & $7.00 \%$ & 50 & $7.40 \%$ & \\
\hline \multicolumn{8}{|c|}{ Alcohol Consumption } \\
\hline - No & 667 & $62.00 \%$ & 215 & $53.80 \%$ & 452 & $67.00 \%$ & *** \\
\hline - Yes & 408 & $38.00 \%$ & 185 & $46.30 \%$ & 223 & $33.00 \%$ & \\
\hline \multicolumn{8}{|l|}{ Tobacco Use } \\
\hline • No & 741 & $68.90 \%$ & 290 & $72.50 \%$ & 451 & $66.80 \%$ & *** \\
\hline - Yes & 60 & $5.60 \%$ & 34 & $8.50 \%$ & 26 & $3.90 \%$ & \\
\hline - Former & 274 & $25.50 \%$ & 76 & $19.00 \%$ & 198 & $29.30 \%$ & \\
\hline \multicolumn{8}{|l|}{ Physical Activity } \\
\hline - No & 615 & $57.20 \%$ & 207 & $51.70 \%$ & 408 & $60.40 \%$ & $* * *$ \\
\hline
\end{tabular}


The mean surgery time was 69.6 minutes for an outpatient The mean time in PACU was 66.33 minutes for outpatient UKA and 68.2 minutes for an inpatient UKA (see Figure 1). The mean surgery time for inpatient UKAs was 1.4 minutes less than mean surgery time for outpatient UKAs.

UKAs and 144.33 minutes for inpatient UKAs (see Figure 1). The mean time in PACU for outpatient UKAs is over 1 hour (78 minutes) less than the mean time in PACU for inpatient UKAs.

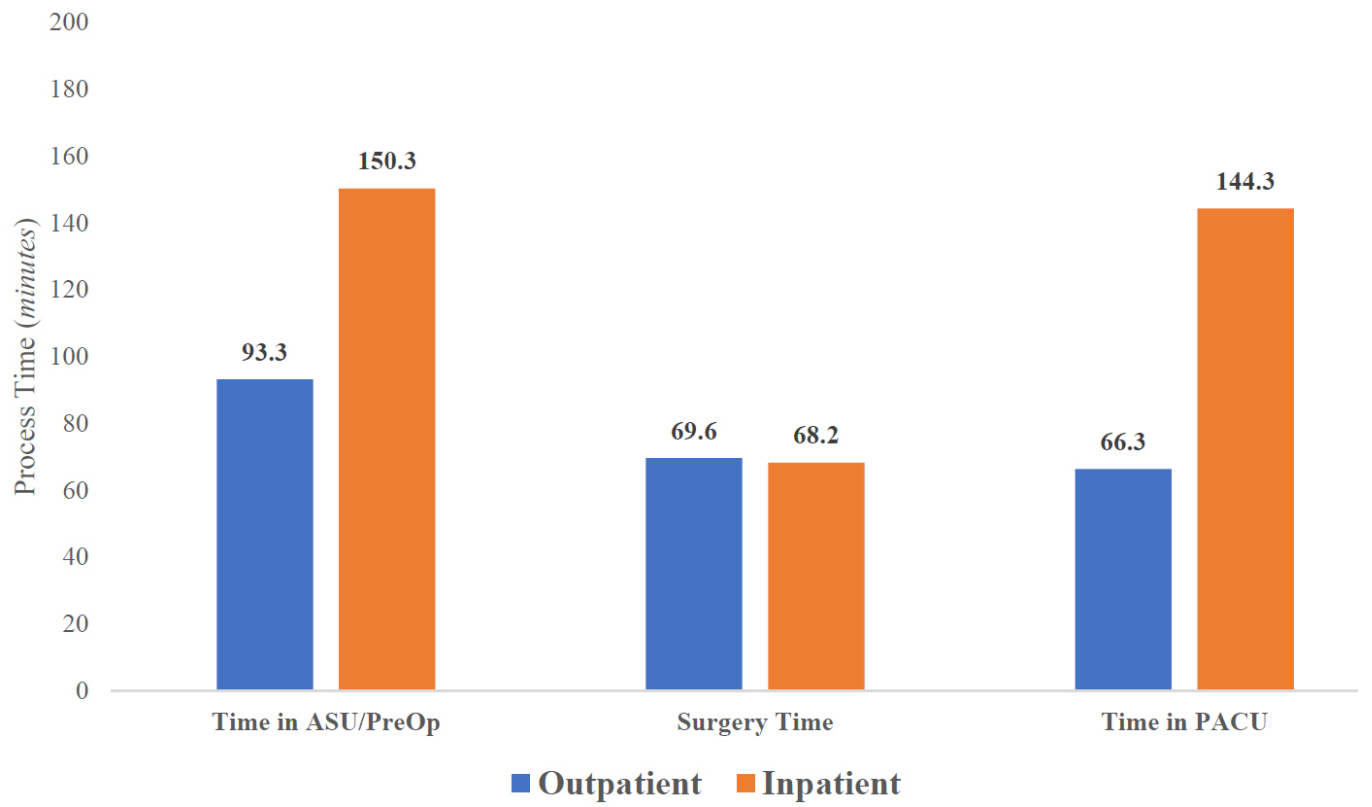

Figure 1. Average process times by setting (minutes)

\subsection{Multivariate statistics}

\section{Process time}

(1) Time in ambulatory surgery unit/Pre-Op

OLS coefficients for associations between demographics, service setting, and social history of the patients show a significant increase in time in ASU/Pre-Op for inpatient vs. outpatient surgical settings. Controlling for these independent variables the time in ASU/Pre-Op for inpatients was 49 minutes longer $(p<.001)$ (see Table 2$)$. Being widowed significantly increased time in ASU/Pre-Op by 11 minutes $(p=.011)$ and being a former smoker decreased time by nearly 8 minutes $(p=.029)$. While statistically significant, these may not be clinically meaningful.

\section{(2) Surgery time}

OLS coefficients for associations between demographics, service setting, and social history of the patients show a significant increase in time in surgery for inpatient vs. outpatient surgical settings. Controlling for these independent variables, the time in ASU/Pre-Op for inpatients was 5 minutes longer $(p<.001)$. The most notable difference, although expected, was the fact that those patients receiving knee implants on both knees had an hour longer time in surgery than their counterparts only receiving one knee implant. Age signifi- cantly decreased time in surgery. In addition, female patients had a significantly shorter surgery time (2.5 minutes less than men, $p=.01$ ), although this may not be clinically meaningful. Black patients had a longer surgery time when compared to white patients ( 7 minutes longer, $p=.032$ ). Marital status, employment status, the type of implant received, tobacco use, physical activity, comorbidities, or alcohol consumption did not impact time in surgery (see Table 3 ).

\section{(3) Time in PACU}

OLS coefficients for associations between demographics, service setting, and social history of the patients show a significant increase in time in PACU for inpatient vs. outpatient surgical settings. Controlling for these independent variables, time in the inpatient setting is longer than the outpatient setting by approximately 78 minutes, although this is not statistically significant $(p=.091)$ (see Table 4$)$. Patients who had regular physical activity were associated with an approximate 10 minutes less time in the PACU $(p=.006)$ when compared to those without.

\section{Discussion}

Overall the demographic characteristics of patients in our population were not markedly different for the inpatients and 
the outpatients. The social history characteristics showed that most patients were nonsmokers, but it appears that current smokers may still be candidates for an outpatient UKA. A higher percentage of patients who are physically active do have the outpatient UKA as compared to the inpatient UKA. This is an interesting finding that could be further developed in future research with examining the relationship of health status and the choice of surgical location.

Table 2. OLS coefficients for time in ASU/Pre-Op

\begin{tabular}{|c|c|c|c|}
\hline Covariates & Coefficient & SE & Sig. \\
\hline \multicolumn{4}{|l|}{ Setting of Surgery } \\
\hline - Inpatient & 48.9 & 3.43 & .000 \\
\hline - Outpatient & Reference & & \\
\hline \multicolumn{4}{|l|}{ Year of Service } \\
\hline • 2009 & -21.533 & 12.709 & .091 \\
\hline - 2010 & -19.787 & 8.487 & .02 \\
\hline - 2011 & -15.115 & 5.303 & .004 \\
\hline - 2012 & -6.257 & 4.601 & .174 \\
\hline - 2013 & 18.126 & 4.044 & .000 \\
\hline - 2014 & Reference & & \\
\hline \multicolumn{4}{|l|}{ Knee } \\
\hline - Left & Reference & & \\
\hline - Right & 0.814 & 2.967 & .784 \\
\hline - Both & 8.721 & 28.05 & .756 \\
\hline \multicolumn{4}{|l|}{ Implant } \\
\hline - Biomet Oxford & Reference & & \\
\hline • Zimmer Zuk & 12.673 & 10.952 & .247 \\
\hline \multicolumn{4}{|l|}{ Age } \\
\hline - Mean & 0.059 & 0.227 & .796 \\
\hline \multicolumn{4}{|l|}{ Gender } \\
\hline - Male & Reference & & \\
\hline - Female & 1.625 & 3.151 & .606 \\
\hline \multicolumn{4}{|l|}{ Race } \\
\hline - Not Specified & -6.678 & 7.33 & .362 \\
\hline - White & Reference & & \\
\hline - Black & -13.797 & 10.145 & .174 \\
\hline \multicolumn{4}{|l|}{ Marital Status } \\
\hline - Not Specified & -20.06 & 22.117 & .365 \\
\hline - Married & Reference & & \\
\hline - Widowed & 12.767 & 5.02 & .011 \\
\hline - Divorced & 8.146 & 8.663 & .347 \\
\hline - Single & 4.103 & 7.23 & .571 \\
\hline - Separated & 19.419 & 24.528 & .429 \\
\hline \multicolumn{4}{|l|}{ Employment Status } \\
\hline - Not Employed & Reference & & \\
\hline - Full Time & 4.481 & 6.238 & .473 \\
\hline - Part Time & -6.471 & 5.821 & .267 \\
\hline \multicolumn{4}{|c|}{ Alcohol Consumption } \\
\hline - No & Reference & & \\
\hline - Yes & 5.104 & 3.184 & .109 \\
\hline \multicolumn{4}{|l|}{ Tobacco Use } \\
\hline • No & Reference & & \\
\hline - Yes & 2.667 & 6.629 & .688 \\
\hline - Former & -7.892 & 3.62 & .029 \\
\hline \multicolumn{4}{|l|}{ Physical Activity } \\
\hline - No & Reference & & \\
\hline - Yes & -0.628 & 3.066 & .838 \\
\hline
\end{tabular}

Note. Dependent Variable is Time in ASU/Pre-op (ASU in to ASU out)
Table 3. OLS coefficients for time in surgery

\begin{tabular}{|c|c|c|c|}
\hline Covariates & Coefficient & $\mathbf{S E}$ & Sig. \\
\hline \multicolumn{4}{|l|}{ Setting of Surgery } \\
\hline - Inpatient & 5.045 & 1.065 & .000 \\
\hline - Outpatient & Reference & & \\
\hline \multicolumn{4}{|l|}{ Year of Service } \\
\hline • 2009 & 17.961 & 3.938 & .000 \\
\hline - 2010 & 23.839 & 2.629 & .000 \\
\hline • 2011 & 14.89 & 1.643 & .000 \\
\hline - 2012 & 7.188 & 1.425 & .000 \\
\hline - 2013 & 0.292 & 1.253 & .816 \\
\hline - 2014 & Reference & & \\
\hline \multicolumn{4}{|l|}{ Knee } \\
\hline - Left & Reference & & \\
\hline - Right & -0.303 & 0.919 & .741 \\
\hline - Both & 61.491 & 8.69 & .000 \\
\hline \multicolumn{4}{|l|}{ Implant } \\
\hline - Biomet Oxford & Reference & & \\
\hline - Zimmer Zuk & -4.509 & 3.393 & .184 \\
\hline \multicolumn{4}{|l|}{ Age } \\
\hline - Mean & -0.183 & 0.07 & .009 \\
\hline \multicolumn{4}{|l|}{ Gender } \\
\hline - Male & Reference & & \\
\hline - Female & -2.504 & 0.976 & .010 \\
\hline \multicolumn{4}{|l|}{ Race } \\
\hline - Not Specified & 3.401 & 2.271 & .135 \\
\hline - White & Reference & & \\
\hline - Black & 6.754 & 3.143 & .032 \\
\hline \multicolumn{4}{|l|}{ Marital Status } \\
\hline - Not Specified & 3.401 & 2.271 & .707 \\
\hline - Married & Reference & & \\
\hline - Widowed & 2.579 & 2.684 & .337 \\
\hline - Divorced & -0.256 & 2.24 & .909 \\
\hline - Single & -9.495 & 7.599 & .212 \\
\hline - Separated & 6.754 & 3.143 & .032 \\
\hline \multicolumn{4}{|l|}{ Employment Status } \\
\hline - Not Employed & Reference & & \\
\hline - Full Time & 1.316 & 1.933 & .496 \\
\hline - Part Time & -2.581 & 1.803 & .153 \\
\hline \multicolumn{4}{|l|}{ Alcohol Consumption } \\
\hline - No & Reference & & \\
\hline - Yes & 0.765 & 0.986 & .438 \\
\hline \multicolumn{4}{|l|}{ Tobacco Use } \\
\hline • No & Reference & & \\
\hline - Yes & 3.703 & 2.054 & .072 \\
\hline • Former & 0.22 & 1.122 & .845 \\
\hline \multicolumn{4}{|l|}{ Physical Activity } \\
\hline • No & Reference & & \\
\hline - Yes & 0.751 & 0.95 & .430 \\
\hline
\end{tabular}

Note. Dependent Variable is Time in Surgery (Surgery Start to Surgery Stop)

Patients having a UKA in the inpatient setting will, on average, spend approximately forty-nine minutes more in the ASU/Pre-Op than their outpatient counterparts. Inpatients are waiting longer in bed, hooked up to IVs, vital signs monitors, and oxygen, waiting to be taken to the operating room. ${ }^{[5]}$ Besides the time factor, patients are taking up space and resources that can be used for other patients scheduled 
for surgery that day. ${ }^{[2]}$ As this time increases, a backlog of patients waiting for surgery in the ASU/Pre-Op causes more strain on the system.

Table 4. OLS coefficients for time in PACU

\begin{tabular}{|c|c|c|c|}
\hline Covariates & Coefficient & SE & Sig. \\
\hline \multicolumn{4}{|l|}{ Setting of Surgery } \\
\hline - Inpatient & 78.019 & 4.316 & .091 \\
\hline - Outpatient & Reference & & \\
\hline \multicolumn{4}{|l|}{ Year of Service } \\
\hline - 2009 & 28.428 & 15.962 & .075 \\
\hline - 2010 & 22.53 & 10.659 & .035 \\
\hline - 2011 & 24.145 & 6.661 & .000 \\
\hline - 2012 & 34.407 & 5.779 & .000 \\
\hline - 2013 & 7.298 & 5.079 & .151 \\
\hline - 2014 & Reference & & \\
\hline \multicolumn{4}{|l|}{ Knee } \\
\hline - Left & Reference & & \\
\hline - Right & -5.395 & 3.726 & .148 \\
\hline - Both & 2.819 & 35.229 & .936 \\
\hline \multicolumn{4}{|l|}{ Implant } \\
\hline - Biomet Oxford & Reference & & \\
\hline • Zimmer Zuk & 1.507 & 13.755 & .913 \\
\hline \multicolumn{4}{|l|}{ Age } \\
\hline - Mean & 0.361 & 0.285 & .206 \\
\hline \multicolumn{4}{|l|}{ Gender } \\
\hline - Male & Reference & & \\
\hline - Female & 4.217 & 3.957 & .287 \\
\hline \multicolumn{4}{|l|}{ Race } \\
\hline - Not Specified & 4.967 & 9.206 & .590 \\
\hline - White & Reference & & \\
\hline - Black & 12.134 & 12.741 & .341 \\
\hline \multicolumn{4}{|l|}{ Marital Status } \\
\hline - Not Specified & -14.765 & 27.778 & .595 \\
\hline - Married & Reference & & \\
\hline - Widowed & 5.887 & 6.305 & .351 \\
\hline - Divorced & 5.583 & 10.88 & .608 \\
\hline - Single & -3.596 & 9.08 & .692 \\
\hline - Separated & -16.296 & 30.806 & .597 \\
\hline \multicolumn{4}{|l|}{ Employment Status } \\
\hline - Not Employed & Reference & & \\
\hline - Full Time & 8.888 & 7.834 & .257 \\
\hline - Part Time & -3.804 & 7.311 & .603 \\
\hline \multicolumn{4}{|l|}{ Alcohol Consumption } \\
\hline - No & Reference & & \\
\hline - Yes & -2.055 & 3.999 & .607 \\
\hline \multicolumn{4}{|l|}{ Tobacco Use } \\
\hline • No & Reference & & \\
\hline - Yes & -0.631 & 8.326 & .940 \\
\hline - Former & -1.06 & 4.547 & .816 \\
\hline \multicolumn{4}{|l|}{ Physical Activity } \\
\hline - No & Reference & & \\
\hline - Yes & -10.636 & 3.85 & .006 \\
\hline
\end{tabular}

Note. Dependent Variable is Time in PACU (PACU in to PACU out)

Patients having a UKA in the outpatient setting will have approximately one minute more in surgery time than their inpatient counterparts. UKAs in the two settings generally utilize the same surgical technique and the same set of stan- dard operating procedures for the surgery, however the inpatient setting will have a longer process time. ${ }^{[9]}$ The UKA standard operating procedure involves the removal of the damaged tissue, ${ }^{[5,10,11]}$ as well as multiple measurements taken throughout the surgery using guides and sizing pieces for the different components of the implant. However, the one minute difference may not, in the end, be financially or clinically meaningful to the patient, payer, or provider. This may be an area of future research to identify the granular differences, if any exist, in the surgery process in order to improve efficiency. ${ }^{[3]}$

Patients having a UKA in the inpatient setting will spend approximately 78 minutes more time in PACU than their outpatient counterparts. Although this was not statistically significant, this is clinically and financially significant. This additional time means that inpatients continue to receive intravenous medications, as well as vital signs monitoring in bed waiting to be admitted to the floor. ${ }^{[12]}$ In other words, not only do the outpatients spend approximately one hour less in the PACU, they also are discharged to home. The time needed for the inpatient bed to be prepared and staffed to accept the patient after discharge from PACU may explain this large time gap. ${ }^{[4,13]}$

Patients having a UKA in the inpatient setting will have approximately 130.34 minutes more total process time than their outpatient counterparts. This study provided evidence that UKAs performed in the outpatient setting may result in time savings.

Overall, other studies conducted up to this point lacked analysis based on procedures transitioning to the outpatient setting. Most, if not all, surgical procedures were originally performed in an inpatient setting due to the lack medical techniques, level of technology support, safety concerns, and the ease of resource centralization. ${ }^{[13]}$ In the inpatient setting contingencies were in place in case there were any types of complications during surgical procedures. However, with improvements in the field of medicine and safety, surgical procedures could be performed outside of the inpatient setting safely. ${ }^{[14,15]}$ With outpatient services, hospitals are able to save on costs, due to less invasive procedures and reduced dependency on inpatient resources. ${ }^{[3]}$ With the outpatient setting as a viable option, patients are discharged for recovery to their homes, instead of being admitted to the hospital. Nevertheless, given the wide variation in how procedures are performed and the supportive care that procedures require, transitioning to the outpatient setting is not a simple task that can be done on a large scale, especially given the current systems in place. Similarly, comparing performance measures of procedures across settings is not something that can be done on a wide scale. Each procedure must be evaluated 
individually to identify how its intricate details are impacted by a move from the inpatient to the outpatient setting.

Although the healthcare system will benefit from this study, future research conducting a procedure-by-procedure approach will be needed to reveal the intricacies of the process time, quality outcomes, and patient satisfaction before a more widespread policy of transitioning procedures to the outpatient setting can be created. That step is necessary mainly due to the lack of wide-scale data that might offer direct comparisons for transitioning to the outpatient setting. Thus, the comparison of outpatient UKAs with inpatient UKAs functions as a stepping-stone in supporting an evidence-based approach to contrasting different procedures and treatments in both the outpatient and inpatient settings and across different variables. This study can be used as a platform for different national and international systems to transition their procedures to the outpatient setting.

There are other potential benefits that UKAs offer. For example, in countries where total knee arthroplasties (TKAs) are prohibitively expensive, or the post-operative care and rehabilitation is not available, UKAs could potentially become more common, especially in the outpatient setting. ${ }^{[16]}$ As UKAs become more common, this study should be repeated in order to analyze surgical data from other physicians in the outpatient and inpatient settings.

The outpatient setting has been important in developing and testing new techniques to improve care. ${ }^{[10]}$ Since physicians that work in freestanding facilities have more discretion and flexibility, they can develop and refine these techniques over time. Furthermore, physicians have more say in the policies and procedures that are used for surgeries in the outpatient setting, which allows for refinements of their techniques. ${ }^{[5,17]}$ These new techniques range from performing different $\mathrm{x}$ ray views, injecting pain medications into the tissue around the joint, requiring patients to walk the day of surgery, and participating in active physical therapy after surgery. The refinement process takes time, since there is an incentive for better outcomes and greater efficiency. ${ }^{[3]}$ The findings of the current study are corroborated by previous studies showing that surgery time is shorter when the procedure is performed in the outpatient setting than the inpatient setting. ${ }^{[3,5]}$

Additionally, most freestanding ambulatory surgery centers are at least partially owned by physicians who perform surgeries at the facility. ${ }^{[18]}$ Due to physician ownership interest, physician owners and physician-non-owners alike may have more stake in the profitability of the facility and there is a heightened incentive to control costs while reducing process time, increasing quality outcomes, and improving patient satisfaction. ${ }^{[10]}$ In general, ambulatory surgery centers may be different from hospitals in three ways, physicians may Published by Sciedu Press select less severe patients to receive the procedure in the outpatient center, physicians may be incentivized to perform efficiently because physician owners not only receive professional fees, but also a share of the facility's profit, and ambulatory surgery centers tend to be specialized in performing a limited set of procedures. This study only focused on one surgical procedure - UKA - to compare outpatient and inpatient settings, both facilities are multi-specialty institutions. Additionally, factors that relate to severity of patients' health status were controlled for in this study to mitigate selection bias that could potentially take place.

Our results should be considered in light of several limitations. This study was dependent on data available from electronic medical records and reports provided by the orthopedic surgeon. Due to the fact that this study only analyzed one physician's patients (in one hospital for inpatients and one ambulatory surgery center for outpatients), external validity and generalizability of the study to other physicians and facilities may be limited. ${ }^{[3]}$ The use of one physician's data, both for the outpatient and inpatient setting, minimizes issues of provider and operative consistency. This in turn strengthens the internal validity as the techniques of performing a UKA are essentially the same. It is important to note that these data were abstracted from the EMR, which resulted in imputation by the research team. This study does not show a causal relationship, it explored associations between time in ASU, surgery time, and time in the PACU and covariates, and the service setting in particular. Comorbidities and Body Mass Index (BMI) are two important factors that may affect surgery time. Although there was a lack of information related to these factors, this study controlled for age, tobacco, alcohol and physical activity, which may correlate with factors such as comorbidities and BMI.

\section{Conclusions}

After comparing outpatient UKAs with inpatient UKAs, the results showed differences, some of them statistically significant, with respect to Process Time. Overall, this study found that total time is approximately 130.34 minutes longer including time in ASU/Pre-Op, surgery time, and time in PACU for inpatients when compared to outpatients. These inefficiencies may have costs associated with them. In addition to time, hospital administrators should consider the impact of shifting procedures to outpatient venues on human resources and material costs. However, for patients who are good candidates for outpatient procedures the benefits of home based recovery cannot be underestimated.

\section{Conflicts of InTEREST Disclosure}

The authors declare they have no conflicts of interest. 


\section{REFERENCES}

[1] Fulton LV, Lasdon LS, McDaniel RR Jr, et al. Including quality, access, and efficiency in healthcare cost models. Hospital Topics. 2008; 86(4): 3-17. PMid: 18922752. https://doi.org/10.3200/HTPS $.86 .4 .3-17$

[2] Berger R, Kusuma S, Sanders S, et al. The feasibility and perioperative complications of outpatient knee arthroplasty. Clinical Orthopaedics \& Related Research. 2009; 467(6): 1443-1449. PMid: 19238499. https : //doi.org/10.1007/s11999-009-0736-7

[3] Fabricant PD, Seeley MA, Rozell JC, et al. Cost Savings From Utilization of an Ambulatory Surgery Center for Orthopaedic Day Surgery. Journal of The American Academy of Orthopaedic Surgeons. 2016; 24(12): 865-871. PMid: 27792057. https ://doi.org/10.5435/ JAAOS-D-15-00751

[4] Jamali A, Scott R, Rubash H, et al. Unicompartmental knee arthroplasty: past, present, and future. American Journal of Orthopedics. 2009; 38(1): 17-23. PMid: 19238263.

[5] Munnich EL, Parente ST. Procedures take less time at ambulatory surgery centers, keeping costs down and ability to meet demand up. Health Affairs. 2014; 33(5): 764-769. PMid: 24799572. https://doi.org/10.1377/hlthaff .2013.1281

[6] Larsen K, Hansen T, Søballe K, et al. Patient-reported outcome after fast-track knee arthroplasty. Knee Surgery, Sports Traumatology, Arthroscopy. 2012; 20(6): 1128-1135. PMid: 22349544. https ://doi.org/10.1007/s00167-012-1919-4

[7] Alexopoulos E. Introduction to multivariate regression analysis. Hippokratia. 2010; 14(Suppl 1): 23-28. PMid: 21487487.

[8] Pohlmann JT, Leitner DW. A comparison of ordinary least squares and Logistic Regression. Ohio Journal of Science. 2003; 103(5): 118-125.

[9] Stieber JR, Brown K, Donald GD, et al. Anterior cervical decompression and fusion with plate fixation as an outpatient pro- cedure. Spine Journal. 2005; 5(5): 503-507. PMid: 16153576 https://doi.org/10.1016/j.spinee.2005.01.011

[10] Borus T, Thornhill T. Unicompartmental knee arthroplasty. The Journal of The American Academy of Orthopaedic Surgeons. 2008; 16(1): 9-18. PMid: 18180388. https://doi.org/10.5435/00124635 $-200801000-00003$

[11] Partial knee replacement is option for some patients: patients find quick return to normal activity. Same-Day Surgery. 2008; 32(3): 34-36.

[12] Haack D. Ambulante Chirurgie/stationsersetzende Leistungen [Outpatient surgery/substitution of inpatient services]. 2010; 12: 259-261.

[13] Gamotis PB, Dearmon VC, Doolittle NO, et al. Inpatient hospital setting vs outpatient satisfaction: a research study. AORN Journal. 1988; 47(6): 1421. https ://doi.org/10.1016/S0001-2092(07)663 18-2

[14] Browne J, Jamieson L, Lewsey J, et al. Case-mix \& patients' reports of outcome in independent sector treatment centres: comparison with NHS providers. BMC Health Services Research. 2008; 8: 1-7. PMid: 18400096. https : //doi.org/10.1186/1472-6963-8-78

[15] Kolisek F, McGrath M, Jessup N, et al. Comparison of outpatient versus inpatient total knee arthroplasty. Clinical Orthopaedics \& Related Research. 2009; 467(6): 1438-1442.

[16] Kurtz S, Ong K, Lau E, et al. Projections of primary and revision hip and knee arthroplasty in the United States from 2005 to 2030. The Journal of Bone and Joint Surgery. American Volume. 2007; 89(4): 780-785. PMid: 17403800.

[17] Chukmaitov AS, Menachemi N, Brown LS, et al. A comparative study of quality outcomes in freestanding ambulatory surgery centers and hospital-based outpatient departments: 1997-2004. Health Services Research. 2008; 43(5p1): 1485-1504.

[18] Liu X. The effect of physician ownership on quality of care for outpatient procedures. Dissertation Abstracts International. 2013; 74 